\title{
O USO DOS DISPOSITIVOS DE COMUNICAÇÃO DA WEB SOCIAL PELAS INSTITUIÇÕES ARQUIVÍSTICAS PÚBLICAS ESTADUAIS BRASILEIRAS
}

\section{THE USE OF SOCIAL WEB COMMUNICATION DEVICES BY THE BRAZILIAN STATE ARCHIVAL INSTITUTIONS}

\author{
Héngret Santos Ferreiraa \\ Raquel do Rosário Santos ${ }^{b}$ \\ Louise Anunciação Fonseca de Oliveira do Amaralc
}

\begin{abstract}
RESUMO
Objetivo: Analisar se e como as instituições arquivísticas públicas estaduais estão utilizando os dispositivos de comunicação da web social para favorecer o acesso à informação ao usuário. Neste artigo são adotadas e discutidas as seguintes temáticas: instituições arquivísticas públicas estaduais; web social e dispositivos de comunicação da web social. Metodologia: Trata-se de um estudo de caráter descritivo, com natureza qualitativa e quantitativa, realizado por meio do método de múltiplos casos, tendo como objeto de estudo as instituições arquivísticas públicas estaduais brasileiras, mais especificamente seus dispositivos de comunicação da web social. O endereço eletrônico desses arquivos foi obtido por meio da lista de instituições arquivísticas estaduais, disponibilizada no website do Conselho Nacional de Arquivos - CONARQ, sendo a segunda etapa uma observação direta nos websites e, por último, uma observação na fanpage das instituições arquivísticas. Resultados: Foi identificado as instituições arquivísticas públicas estaduais que disponibilizam os dispositivos de comunicação da web social, bem como quais são esses dispositivos e como vem ocorrendo o uso dos dispositivos da web social pelas instituições arquivísticas públicas estaduais. Conclusões: Os gestores precisam se tornar ativos e conscientes sobre a importância de disponibilizar um espaço formal na web social que garanta a interação e colaboração do usuário.
\end{abstract}

Descritores: Arquivos Públicos Estaduais. Web social - arquivo. Dispositivos de

a Bacharel em Arquivologia pela Universidade Federal da Bahia (UFBA). E-mail: hengret.sf@gmail.com.

b Doutora em Ciência da Informação pela Universidade Federal da Paraíba (UFPB). Docente do Instituto de Ciência da Informação da Universidade Federal da Bahia (UFBA). E-mail: quelrosario@gmail.com.

c Doutoranda em Ciência da Informação pela Universidade Federal Fluminense (UFF). Arquivista da Escola Politécnica da Universidade Federal da Bahia (UFBA). E-mail: soulouise@gmail.com. 
Comunicação da Web Social - arquivo.

\section{INTRODUÇÃO}

Os recursos da web social apresentam-se como dispositivos que potencializam o compartilhamento e a produção da informação, favorecendo que os sujeitos sejam mais participativos e colaborativos, a partir da interação, atuando como protagonistas nesse meio. Essa adoção das tecnologias digitais conduz a uma ressignificação do processo de acesso e uso, ressituando os sujeitos na construção, avaliação, reformulação do conhecimento e na realização de suas atividades sociais.

A web social é um fenômeno relativamente recente e correlaciona-se com o contexto maior das web 3.0 e 4.0, cujo cerne conceitual é a participação do usuário. Ao vislumbrar um panorama atual, pode-se perceber a intensificação do uso da internet e dos dispositivos da web social (a exemplo do facebook, twitter, youtube, whatsapp, dentre outros), oferecendo às instituições arquivísticas a possibilidade de dispor da web como um espaço digital a ser utilizado para facilitar o acesso e uso à informação pública.

Nesse contexto, as instituições arquivísticas públicas estaduais precisam perceber o espaço virtual, a web social e seus recursos de comunicação, como importantes aliados, logo que podem potencializar o acesso, uso, a disseminação e construção de informações e conhecimentos.

Em 2012, Oliveira sinalizou um uso incipiente dos dispositivos da web social pelas vinte e seis instituições arquivísticas públicas estaduais listadas pelo CONARQ. Os Estados do Sul e do Sudeste são os que mais se destacavam neste cenário, em especial o Arquivo Público do Estado de São Paulo. O twitter era o dispositivo da web social mais utilizado pelas instituições arquivísticas estaduais. Em 2013, Duarte compara o uso dos dispositivos facebook e twitter em duas instituições arquivísticas públicas estaduais brasileiras, o Arquivo Público do Estado do Rio Grande do Sul (APERS) e do Estado de São Paulo (APESP), demonstrando as estratégias de difusão que esses arquivos utilizavam. Em 2017, o estudo de Jorente e Batista evidenciava o twitter ao apresentar e 
sugerir iniciativas inovadoras de Curadoria Digital para compartilhamento de informações preservadas pelos Arquivos Públicos Permanentes (APP), demonstrando, mais uma vez, a utilização dos recursos de comunicação da web social no contexto das instituições arquivísticas públicas. Por fim, vale destacar que o estudo de Ferreira (2018) suscitou as discussões presentes neste artigo, uma vez que a transferência e o acesso à informação arquivística pública estadual no espaço da web social necessitam de aprofundamento para subsidiar a teoria e a práxis.

A partir do reconhecimento da importância desses dispositivos para as instituições arquivísticas estaduais justifica-se a realização desta pesquisa, cujo objetivo geral consistiu em analisar quais as instituições arquivísticas públicas estaduais brasileiras estão utilizando os dispositivos de comunicação da web social para favorecer o acesso à informação ao usuário.

Para alcançar o objetivo geral foram definidos os seguintes objetivos específicos: a) identificar quais instituições arquivísticas públicas estaduais brasileiras disponibilizam os dispositivos de comunicação da web social e quais são esses dispositivos; b) investigar como vem ocorrendo o uso dos dispositivos da web social pelas instituições arquivísticas estaduais objeto deste estudo.

$O$ presente artigo amplia as reflexões que decorrem de estudos anteriores, empreendidos por autores no âmbito da literatura acadêmicocientífica nacional das áreas de Arquivologia e de Ciência da Informação. Destacam-se os autores que tratam sobre o paradigma participativo na transferência da informação arquivística como: Silva (1996) e Silva e Marinho Júnior (1998), no que se refere à transferência da informação arquivística na web destacam-se Jardim (2011), Mariz (2012), Archer e Cianconi (2010). Por sua vez, discorrem acerca da web social, na área de arquivos, Oliveira (2012), Jorente e Batista (2017), Duarte (2018) e Ferreira (2018). Esse referencial teórico e empírico será tratado com maior aprofundamento na próxima seção. 


\section{AS INSTITUIÇÕES ARQUIVÍSTICAS ENQUANTO AMBIENTE DE ACESSO À INFORMAÇÃO}

Os arquivos podem ser entendidos como conjuntos de documentos produzidos, recebidos e acumulados por órgãos públicos e entidades privadas, em decorrência do exercício de atividades específicas, bem como por pessoa física, qualquer que seja o suporte da informação ou a natureza dos documentos. (BRASIL, 1991). Também é considerado como arquivos, as instituições responsáveis por recolher, ordenar e dar acesso aos documentos arquivísticos. (CORTÊS, 1996). Percebe-se que, tanto no primeiro conceito quanto no segundo, o arquivo está ligado à preservação da memória, organização e a possibilidade de acesso ao documento.

O arquivo como instituição não é uma ideia que foi pensada recentemente, pois existem desde tempos antigos. Como enfatiza Schellenberg (2006) os gregos que valorizavam a importância de guardar os seus documentos.

Os arquivos como instituição, provavelmente, tiveram origem na antiga civilização grega. Nos séculos $\mathrm{V}$ e VI a.c. os atenienses guardavam seus documentos de valor no templo da mãe dos deuses, isto é, no Metroon, junto à corte de justiça na praça pública em Atenas. No templo conservavam-se os tratados, leis, minutas da assembléia popular e demais documentos oficiais. (SCHELLENBERG, 2006, p. 25)

Vale ressaltar que esses arquivos não eram destinados ao acesso público, só uma parcela bem restrita da sociedade poderia consultá-los, além de que esses existiam para servir a administração do governo.

Já no contexto da Revolução Francesa, em 1789, a situação dos arquivos passou por uma transformação, pois a reorganização do governo francês impactou diretamente, uma vez que começou-se a centralizar todos os documentos do Estado em um único lugar, o que até então era chamado de Arquivo da Assembleia, no qual posteriormente passou a ser o Arquivo Nacional da França. (SCHELLENBERG, 2006).

Com a centralização dos arquivos, a França passou a se preocupar com a guarda de seus documentos e, a partir desse momento, o acesso aos 
Héngret Santos Ferreira, Raquel do Rosário Santos, Louise Anunciação Fonseca de Oliveira do Amaral

O uso dos dispositivos de comunicação da web social pelas instituições arquivísticas públicas estaduais brasileiras

documentos foi aberto para toda a sociedade que, até então, não tinha acesso permitido. Dessa forma, a institucionalização do Arquivo Nacional da França deu origem ao primeiro arquivo público com possibilidade de acesso livre para a sociedade, servindo de exemplo para a implantação dos arquivos públicos na Europa e nas Américas, mas respeitando a particularidade e necessidade de cada país.

No contexto brasileiro, também houve a criação dos arquivos públicos, começando com o Arquivo Nacional, criado em 1838 durante o regime imperial, com a função de salvaguardar os documentos públicos. (CORTÊS, 1996). Essa função do Arquivo Nacional é ampliada mais tarde, tendo a finalidade de implementar e acompanhar a política nacional de arquivos, através da gestão, tratamento, recolhimento, preservação e disseminação dos documentos públicos do país, garantindo o acesso livre a todo o cidadão e dando suporte às ações do governo. (BRASIL, 1991).

Já as instituições arquivísticas públicas estaduais foram criadas somente na implantação da República no Brasil, com o reconhecimento da importância dessas instituições no país, conforme Jardim (2011, p. 3), apontando que "Tais instituições nascem associadas à invenção do Estado nacional e a necessidade de construção de uma memória nacional que desse suporte à nacionalidade como componente ideológico do Estado burguês nascente."

Com a criação da Lei no 8.159/91 - Lei de Arquivos - é explicitado o que compete às instituições arquivísticas públicas quanto a sua organização e administração, incluindo as instituições arquivísticas públicas estaduais. Sendo que as instituições arquivísticas estaduais possuem a função de recolher e tratar os documentos públicos que já cumpriram a finalidade para a qual foram criados, disponibilizando acesso e garantindo o direito do cidadão à informação pública, como retrata Belloto (2014, p. 133):

[...] a sociedade faz dos arquivos públicos usos multifacetados, valendo-se dos seus documentos como registros fidedignos, necessários à vida civil, pessoal e profissional de seus integrantes, assim como lhe permitindo melhor compreender a identidade cultural de sua comunidade e a evolução da sua história, e o desenvolvimento das relações entre o cidadão e o Estado. 
Logo, as instituições arquivísticas públicas estaduais são espaços em que o cidadão ou pesquisador pode ter acesso à informação que necessita, contribuindo para a garantia de direitos e liberdade de informação. Para tanto, essas entidades precisam, além de cumprir as suas funções básicas de recolhimento, gestão e acesso, se adequar às necessidades e realidade dos usuários. Com o advento da internet e das tecnologias da informação, o usuário das instituições arquivísticas espera que esse ambiente de acesso à informação acompanhe a evolução da comunicação.

A partir dessa reflexão, as instituições arquivísticas precisam se mostrar no meio eletrônico/digital, expondo suas funções, seus serviços, seus documentos de acesso público e eventos realizados no espaço virtual chamado web. Segundo Mariz (2012, p. 62), a disponibilização dos acervos arquivísticos na rede traz muitas vantagens como a facilidade de acesso, atingindo um público maior, além da ampliação do atendimento aos pesquisadores e uma divulgação mais expressiva.

\section{A WEB SOCIAL E A SUA APLICAÇÃO NAS INSTITUIÇÕES ARQUIVÍSTICAS}

A evolução da internet e seus recursos trouxeram novos conceitos. Entre esses, a web é um conceito que engloba a disponibilização de informações na rede eletrônica. Até o ano de 2005, com a chamada web 1.0, ocorria uma interação com apenas dois objetivos: a de produzir e de consumir informação, efetivados em fluxos de informações distintos. (SILVA, 1996).

Nesse contexto, instalou-se um novo conceito: a web 2.0 ou web social. A web social apresenta características diferentes da anterior: na web 1.0, a forma de comunicação era de sujeito para sujeito, sujeito para instituição e vice-versa. (ARCHER; CIANCONI, 2010). Dessa maneira, a web 1.0 não tinha a característica participativa. Logo, a web 2.0 apresenta a ideia de interação, integração, compartilhamento e ambiente coletivo, como explicita Garcia e Vieira (2010, p. 18):

A Web 2.0 possibilita a interação por meio de suas ferramentas 
que não demandam conhecimento prévio sobre linguagens informáticas. Permite que as páginas da Web modifiquem sua estrutura e tornem-se dinâmicas e, aos usuários permite expor o conhecimento tácito, ou seja, o conhecimento próprio, interagindo com outros usuários, obtendo novas perspectivas que combinado a outras informações constroem o conhecimento coletivo.

Nesse contexto, é possível que o sujeito seja também produtor da informação, disponibilizando, compartilhando e interagindo com outros sujeitos e ambientes, dando ênfase ao coletivo, tornando este ambiente virtual um espaço de colaboração, com facilidades e motivações para trocas de experiências e opiniões. (ARCHER; CIANCONI, 2010). Assim, a web social oferece recursos para que os sujeitos interajam no ambiente virtual, facilitando a comunicação e propiciando mais interação por meio do uso de um conjunto de dispositivos que facilitam a criação e o compartilhamento de informações.

Neste processo, Silva e Marinho Júnior (1998) ressaltam a importância da tríade técnicos, documentos e usuários, como também da relevância da participação dos usuários no ambiente arquivístico, ao afirmarem que:

Partilhar com a coletividade [...] é reconhecer que ela tem um peso enorme nas decisões sobre o que deve ou não ser guardado, que valores e referências de sua identidade merecerão uma atitude mais efetiva de proteção. Esta partilha, entretanto, só poderá ser alcançada pela participação, e isto implica abrir o arquivo à comunidade, trazendo para perto de si os usuários da instituição dispostos a estabelecer, juntamente com a equipe do órgão, uma relação mais qualitativa com os arquivos. (SILVA; MARINHO JÚNIOR, 1998, p. 26, grifo nosso).

Com a ampliação dos conteúdos na web também foi necessário criar metodologias e recursos para organização e recuperação das informações disponíveis nos ambientes virtuais. Dessa maneira, Paletta e Mucheroni (2014, p. 76), ao tratarem sobre web 3.0 ou web semântica afirmam que

A Web 3.0 é uma das grandes propostas para o futuro da
internet, a partir do conceito de Linked Data, com o uso de base
de dados com estruturas semânticas e servidores SPARQL.
Será ela que definitivamente organizará todas as informações
que estejam na internet, proporcionará que o desenvolvimento
de aplicativos baseados na Web sejam Open-Source e
viabilizará uma grande interatividade em diversas áreas da Web. 
A partir da reflexão dos autores, pode-se observar que os recursos da web semântica auxiliam os sujeitos na recuperação da informação, pois percebeu-se que não basta a disponibilização de conteúdos, mas é necessária a organização para que os sujeitos possam acessar e utilizar essas informações. Dessa maneira, pode-se afirmar que não existe uma sobreposição entre a web social e a web semântica, visto que os conceitos e as funcionalidades focalizam em objetivos diferentes, porém complementares.

Vale ainda destacar a existência, mais recente, do conceito da web 4.0 ou webOS, segundo Nascimento e Quintão (2011) "As transformações tecnológicas, o aumento de largura de banda e a grande expansão na quantidade de acessos por parte dos usuários são fatores importantes que contribuem para o crescimento e a aplicabilidade dessa tendência que é a quarta geração da Web." Uma das principais características da web 4.0 é a ampliação da interação entre os sujeitos, que ocorre em tempo real, o que torna a comunicação mais dinâmica.

Nesse contexto, de diferentes recursos virtuais que intensificam a interação entre os sujeitos, as organizações passaram a se inserir e utilizar os dispositivos da web para ampliar sua visibilidade, prospectar o perfil, as demandas e expectativas dos sujeitos, comunicando-se com eles para fornecer serviços e produtos que atendam suas necessidades. Assim, é relevante que as instituições arquivísticas também adotem os recursos da web, pois "[...] a inclusão da tecnologia web no cotidiano dos usuários e também nas atividades de prestação de serviços dos arquivos produz novos fluxos e novos usos de informação." (ARCHER; CIANCONI, 2010, p. 62).

A partir do que foi discutido, percebe-se a relevância de fortalecer os conceitos de participação ativa dos usuários no ambiente das instituições arquivísticas, visto que são esses sujeitos sociais a razão de sua existência. Os dispositivos de comunicação disponíveis na web vêm ampliar, para além dos ambientes físicos, a participação dos usuários, haja vista que favorecem a interlocução entre os usuários e entre eles e a instituição arquivística. 
Os dispositivos de comunicação da web social possuem diferentes características e funções, pois alguns possibilitam o compartilhamento de vídeos ou fotos, outros são para criação de pequenas publicações. Pode-se observar que os dispositivos citados apresentam distintas características, as quais podem ser aplicadas nas instituições arquivísticas. Esses dispositivos podem ser usados de diferentes maneiras, citando como exemplo o blog que funciona como um canal de notícias da instituição arquivística através da publicação de posts que se assemelha a um wiki, um canal de elaboração de conteúdo colaborativo.

Já o twitter permite a elaboração de informações sucintas, favorecendo uma comunicação mais objetiva e de forma rápida. O flickr e instagram, por sua vez, tem a função de compartilhamento de imagens, servindo para a exibição de uma possível exposição virtual. O youtube tem a função de compartilhamento de vídeos, pode ser usado para divulgar os serviços e eventos realizados no arquivo, por meio da imagem em movimento. Por fim, o facebook pode servir como um ambiente de compartilhamento de informações, além de poder agregar os outros dispositivos citados a sua plataforma.

A partir dessa contextualização, Garcia e Vieira (2010, p. 25) destacam que, "[...] perante o crescente aumento da disponibilidade de novas ferramentas da Web 2.0, as unidades de informação devem escolher aquela que se adéque melhor com o perfil dos seus usuários e dos serviços por ela disponibilizadas." Assim, é imprescindível que a instituição arquivística adote métodos, técnicas e tecnologias para favorecer a aproximação com o usuário e apoiá-lo no acesso à informação, entre esses recursos destacam-se os dispositivos da web social.

A web social em instituições arquivísticas ainda é um tema pouco debatido e exemplificado nas pesquisas nacionais no âmbito da Arquivologia. Mas, mesmo com o número inexpressivo de pesquisas referente a esse tema, é perceptível o interesse dos pesquisadores em buscar, identificar e analisar elementos dos dispositivos para serem aplicados nas instituições arquivísticas.

Tanto a pesquisa de Oliveira (2012) quanto a pesquisa de Duarte (2013) tratam do uso dos dispositivos de comunicação da web social pelas instituições arquivísticas públicas. Oliveira (2012) sinalizou um uso incipiente dos 
dispositivos da web social pelas vinte e seis instituições arquivísticas públicas estaduais listadas, naquele ano, pelo CONARQ. Para autora, ainda é preciso refletir mais sobre a importância desses espaços virtuais para uma participação mais ativa do usuário.

Por sua vez, Duarte (2013) compara o uso dos dispositivos em duas instituições arquivísticas públicas estaduais brasileiras e demonstra as estratégias de divulgação que estas utilizam. A autora constatou que as estratégias utilizadas entre as instituições supracitadas diferem, no sentido de que o APERS possui uma equipe atualizando frequentemente as suas redes sociais, com informações sobre os mais variados assuntos, mas ainda assim priorizando a difusão da própria instituição. Por outro lado, o APESP se detinha às publicações sobre o próprio arquivo, como eventos e materiais disponíveis em seu website. Pode-se constatar duas metodologias de utilização dos dispositivos da web social, evidenciando que cada instituição os adotará mediante sua realidade.

Jorente e Batista (2017) apresentam iniciativas e sugestões que o twitter oferece às instituições arquivísticas, em ações culturais organizadas pelo Design da Informação (DI) e caracterizadas como de Curadoria Digital, como a de narrações de eventos históricos, concomitantemente à publicação de documentos de acervo digitalizado e custodiado fisicamente pela instituição.

A partir das considerações explicitadas por esses autores, percebe-se a relevância dos dispositivos de comunicação da web social no que tange à divulgação dos serviços e produtos arquivísticos, assim como na potencialização da participação mais ativa dos usuários nesse ambiente e na ressignificação das atividades das instituições arquivísticas públicas brasileiras. Assim, ao adotarem esses dispositivos da web social, essas instituições poderão propiciar um espaço de diálogo e interação com e entre os usuários, aproximando-os do seu ambiente.

A partir desse panorama empírico ratifica-se a relevância de desenvolver pesquisas que tratem sobre o uso dos recursos de comunicação da web social pelas instituições arquivísticas públicas estaduais brasileiras e como tais dispositivos favorecem o acesso à informação pelo usuário. 


\section{PROCEDIMENTOS METODOLÓGICOS}

Este estudo caracteriza-se como descritivo que, segundo Gil (2002, p. 42), "[...] têm como objetivo primordial a descrição das características de determinada população ou fenômeno ou, então, o estabelecimento de relações entre variáveis." Assim, no contexto deste estudo, realizou-se uma descrição do uso dos dispositivos de comunicação da web social pelas instituições arquivísticas públicas brasileiras.

Segundo os procedimentos, esta pesquisa se caracterizou como estudo de múltiplos casos que, segundo Mazzotti (2006, p. 640), identifica como "[...] vários estudos que são conduzidos simultaneamente: vários indivíduos (como, por exemplo, professores alfabetizadores bem-sucedidos), várias instituições (diferentes escolas que estão desenvolvendo um mesmo projeto)". Logo, abrange mais de um objeto de investigação, não se restringindo a um único caso.

Este trabalho teve como universo de investigação as instituições arquivísticas públicas estaduais brasileiras, por serem ambientes que preservam, organizam, disseminam e possibilitam o acesso à memória das instituições públicas, auxiliando no fortalecimento da identidade e na garantia de direitos dos sujeitos sociais. Todavia, por sua extensão, tornou-se necessário trabalhar com uma amostra. Para integrar a amostra, foram selecionadas aquelas instituições que possuíam dispositivos de comunicação da web social.

Quanto aos procedimentos de coleta de dados, foi realizado um primeiro mapeamento nos websites das instituições arquivísticas estaduais brasileiras, no período de 16 a 19 de abril de 2018, sendo atualizado nos períodos de 9 a 12 de janeiro de 2019 e de 13 a 19 de maio de 2020, o que possibilitou um processo comparativo da realidade dessas instituições no espaço virtual, na disponibilização e no uso dos recursos de comunicação da web social. Esse mapeamento foi realizado a partir do website do Conselho Nacional de Arquivos - CONARQ, como também nos do Governo de cada estado à procura dos possíveis endereços eletrônicos das instituições públicas, não localizados no CONARQ. Desse modo, em 2018, foram localizados dezoito (18) websites ativos 
de instituições arquivísticas estaduais e, em 2020, dezesseis (16), de um total de vinte e quatro (24). Quanto à verificação efetuada em 2019, não houve alteração nos resultados obtidos em 2018.

Após esta identificação, foi realizada uma pesquisa, através de uma observação direta dentro desses websites, para localizar os links que direcionavam para os dispositivos de comunicação da web social. Assim, em 2018, foram localizadas cinco (5) instituições que possuíam links para os dispositivos de comunicação em seus respectivos websites. Em 2020, apenas quatro (4) instituições se mantiveram com os links disponibilizados.

Depois da verificação dos websites que possuíam links para os dispositivos, foi realizada uma pesquisa, por meio de observação direta no facebook, no período de 16 a 19 de abril de 2018, por ser o dispositivo que apareceu em quantidade mais expressiva na listagem dos adotados pelas instituições arquivísticas públicas estaduais. Em 2020, o instagram passa a ser outro dispositivo incorporado pelas instituições de maneira tão expressiva quanto o facebook. Entretanto, a observação direta manteve-se apenas no facebook, com o intuito de averiguar: a) as modificações durante esses períodos (2018 e 2020); b) as instituições arquivísticas que possuem uma página oficial no facebook, mas não relatam essa informação em seus websites; c) informações utilitárias sobre a equipe colaboradora, os contatos, a localização física, histórico e missão das instituições arquivísticas e d) frequência de atualização das postagens. Vale destacar que foi utilizado um roteiro para observação sistemática das informações nas fanpages. Em vista disto, as informações coletadas alimentaram um banco de dados da pesquisa para posterior organização e análise.

No processo de coleta de dados também foi identificado, tanto em 2018 quanto em 2020, que, apesar de algumas instituições não possuírem links para o website, ou até mesmo não apresentarem site, elas possuíam uma página no facebook.

Quanto aos procedimentos de análise dos dados coletados foram tanto quantitativos quanto qualitativos, pois, no primeiro momento, identificou-se e 
Héngret Santos Ferreira, Raquel do Rosário Santos, Louise Anunciação Fonseca de Oliveira do Amaral

O uso dos dispositivos de comunicação da web social pelas instituições arquivísticas públicas estaduais brasileiras

quantificou-se as instituições arquivísticas públicas estaduais que utilizavam os dispositivos de comunicação da web social e quais eram esses dispositivos. No segundo momento foram observadas e analisadas as informações disponibilizadas nos dispositivos identificados, a partir da abordagem qualitativa.

\section{AS INSTITUIÇÕES ARQUIVÍSTICAS PÚBLICAS ESTADUAIS BRASILEIRAS E A DISPONIBILIZAÇÃO DOS RECURSOS DE COMUNICAÇÃO DA WEB SOCIAL: APRESENTAÇÃO E DISCUSSÃO DOS RESULTADOS}

Para responder ao objetivo desta pesquisa foi realizado um levantamento daquelas instituições arquivísticas públicas estaduais que possuem websites, a partir da página do CONARQ, no ano de 2018, e posteriormente foi realizado um novo levantamento no ano de 2020. Conforme o Quadro 1, de um total de vinte e quatro (24) instituições arquivísticas estaduais, identificadas em 2018, dezoito (18) possuíam endereços eletrônicos ativos. Em 2020, identificou-se 16 instituições arquivísticas que possuem websites ativos, uma vez que duas instituições arquivísticas estavam com suas páginas fora do ar.

Quadro 1 - Instituições arquivísticas públicas estaduais brasileiras que possuem websites ativos

\begin{tabular}{|l|l|l|}
\hline $\begin{array}{l}\text { Instituições arquivísticas públicas } \\
\text { estaduais brasileiras }\end{array}$ & $\begin{array}{c}\text { Endereços eletrônicos } \\
2018\end{array}$ & $\begin{array}{c}\text { Endereços eletrônicos } \\
2020\end{array}$ \\
\hline Arquivo Público do Distrito Federal & www.arpdf.df.gov.br/ & www.arpdf.df.gov.br/ \\
\hline Arquivo Público do Estado da Bahia - APEB & www.fpc.ba.gov.br & www.fpc.ba.gov.br \\
\hline Arquivo Público de Alagoas & arquivopublico.al.gov.br/ & arquivopublico.al.gov.br/ \\
\hline Arquivo Histórico Estadual de Goiás & www.agepel.go.gov.br & Website não localizado \\
\hline Arquivo Público Mineiro & www.cultura.mg.gov.br & www.siaapm.cultura.mg.gov \\
.br
\end{tabular}


Héngret Santos Ferreira, Raquel do Rosário Santos, Louise Anunciação Fonseca de Oliveira do Amaral

O uso dos dispositivos de comunicação da web social pelas instituições arquivísticas públicas estaduais brasileiras

\begin{tabular}{|c|c|c|}
\hline $\begin{array}{l}\text { Instituições arquivísticas públicas } \\
\text { estaduais brasileiras }\end{array}$ & $\begin{array}{l}\text { Endereços eletrônicos } \\
\qquad 2018\end{array}$ & $\begin{array}{l}\text { Endereços eletrônicos } \\
2020\end{array}$ \\
\hline \multicolumn{3}{|c|}{ (continuação do Quadro 1) } \\
\hline $\begin{array}{l}\text { Arquivo Público do Estado de Santa } \\
\text { Catarina }\end{array}$ & $\begin{array}{l}\text { www.sea.sc.gov.br/index. } \\
\text { php?option=com_content } \\
\text { \&task=view\&id=90\&ltemi } \\
\text { d=248\&lang= }\end{array}$ & $\begin{array}{l}\text { www.sea.sc.gov.br/index. } \\
\text { php?option=com_content } \\
\text { \&task=view\&id=90\&ltemi } \\
d=248 \text { \&lang= }\end{array}$ \\
\hline Arquivo Público do Estado de São Paulo & $\begin{array}{l}\text { www.arquivoestado.sp.g } \\
\text { ov.br/ }\end{array}$ & $\begin{array}{l}\text { www.arquivoestado.sp.g } \\
\text { ov.br/ }\end{array}$ \\
\hline Arquivo Público do Estado do Amazonas & www.sead.gov.br & $\begin{array}{l}\text { http://servicos.sead.am.g } \\
\text { ov.br/arquivopublico/ }\end{array}$ \\
\hline Arquivo Público do Estado do Ceará & $\begin{array}{l}\text { www.secult.ce.gov.br/ind } \\
\text { ex.php/equipamentos- } \\
\text { culturais/arquivo-publico }\end{array}$ & $\begin{array}{l}\text { https://mapacultural.secul } \\
\text { t.ce.gov.br/espaco/499/ }\end{array}$ \\
\hline Arquivo Público do Estado do Espírito Santo & www.ape.es.gov.br/ & www.ape.es.gov.br/ \\
\hline Arquivo Público do Estado do Maranhão & www.cultura.ma.gov.br/ & $\begin{array}{l}\text { http://casas.cultura.ma.g } \\
\text { ov.br/apem/\# }\end{array}$ \\
\hline $\begin{array}{l}\text { Superintendência de Arquivo Público do } \\
\text { Mato Grosso }\end{array}$ & www.apmt.mt.gov.br & www.apmt.mt.gov.br \\
\hline $\begin{array}{l}\text { Arquivo Público Estadual do Mato Grosso } \\
\text { do Sul }\end{array}$ & $\begin{array}{l}\text { www.arquivopublico.ms.g } \\
\text { ov.br/ }\end{array}$ & $\begin{array}{l}\text { http://www.fundacaodecu } \\
\text { Itura.ms.gov.br/arquivo- } \\
\text { publico-estadual-de- } \\
\text { mato-grosso-do-sul-ape/ }\end{array}$ \\
\hline $\begin{array}{l}\text { Departamento Estadual de Arquivo Público } \\
\text { do Paraná }\end{array}$ & $\begin{array}{l}\text { www.arquivopublico.pr.g } \\
\text { ov.br/ }\end{array}$ & $\begin{array}{l}\text { www.arquivopublico.pr.g } \\
\text { ov.br/ }\end{array}$ \\
\hline Arquivo Público do Estado do Piauí & $\begin{array}{l}\text { www.arquivopublico.pi.go } \\
\text { v.br/index.php }\end{array}$ & $\begin{array}{l}\text { www.arquivopublico.pi.go } \\
\text { v.br/index.php }\end{array}$ \\
\hline Arquivo Público do Estado do Rio de Janeiro & www.aperj.rj.gov.br & www.aperj.rj.gov.br \\
\hline $\begin{array}{l}\text { Arquivo Público do Estado do Rio Grande do } \\
\text { Sul }\end{array}$ & www.apers.rs.gov.br & www.apers.rs.gov.br \\
\hline
\end{tabular}

Fonte: Dados da pesquisa, 2020

A partir desses dados, pode-se afirmar que parte significativa das instituições arquivísticas estaduais vêm disponibilizando um ambiente oficial na web para informar ao cidadão sobre seus produtos e serviços, entre outras informações de interesse. Visto que, de acordo com o Quadro 2, apenas 6 delas, em 2018, não tiveram seus websites identificados. Em 2020, o total de 
Héngret Santos Ferreira, Raquel do Rosário Santos, Louise Anunciação Fonseca de Oliveira do Amaral

O uso dos dispositivos de comunicação da web social pelas instituições arquivísticas públicas estaduais brasileiras

instituições subiu para 8, pois, como foi explicitado, duas instituições estão com website inativo.

Quadro 2 - Instituições arquivísticas públicas estaduais brasileiras com websites não identificados

\begin{tabular}{|c|c|}
\hline \multicolumn{2}{|c|}{ Instituições arquivísticas públicas estaduais sem websites } \\
\hline 2018 & 2020 \\
\hline Arquivo Estadual de Roraima & Arquivo Estadual de Roraima \\
\hline Arquivo Público Estadual de Sergipe & Arquivo Público Estadual de Sergipe \\
\hline Divisão de Arquivo Público do Estado do Acre & Divisão de Arquivo Público do Estado do Acre \\
\hline Arquivo Público Estadual do Amapá & Arquivo Público Estadual do Amapá \\
\hline Arquivo Público do Estado do Pará & Arquivo Público do Estado do Pará \\
\hline $\begin{array}{l}\text { Arquivo Público Estadual do Rio Grande do } \\
\text { Norte }\end{array}$ & $\begin{array}{l}\text { Arquivo Público Estadual do Rio Grande do } \\
\text { Norte }\end{array}$ \\
\hline & Arquivo Histórico Estadual de Goiás \\
\hline & Arquivo Público Estadual Jordão Emerenciano \\
\hline
\end{tabular}

Fonte: Dados da pesquisa, 2020

Contudo, destaca-se a relevância desse espaço virtual - os websites das instituições arquivísticas públicas estaduais na disponibilização de informações relevantes ao usuário, o que poderá aproximá-lo e favorecer o uso dos seus produtos e serviços arquivísticos. Assim, mesmo sendo em quantidade reduzida, é importante que aqueles que não possuem websites possam refletir sobre a necessidade da disponibilização de um espaço formal na web, como afirmam Souza e Cândido (2014) ao explicitarem que é fundamental que as instituições arquivísticas se adaptem ao ambiente da web e disponibilizem sites que as promovam e auxiliem na troca de experiências.

Após alcançar esses resultados, como demonstrado no Quadro 3, foi realizada uma pesquisa nos websites das instituições arquivísticas públicas estaduais, com objetivo de identificar os seus dispositivos de comunicação da web social. Dessa maneira, das 18 instituições que possuem websites ativos, apenas cinco 5 delas informavam sobre a existência dos seus dispositivos da web social, em 2018 e 2020. Além disso, em 2020, nos websites ativos constatou-se um aumento de dispositivos ofertados, a exemplo da incorporação do instagram e a manutenção das fanpages e do twitter.

Quadro 3 - Instituições arquivísticas públicas estaduais que disponibilizam dispositivos de comunicação da web social em seus websites 
Héngret Santos Ferreira, Raquel do Rosário Santos, Louise Anunciação Fonseca de Oliveira do Amaral

O uso dos dispositivos de comunicação da web social pelas instituições arquivísticas públicas estaduais brasileiras

\begin{tabular}{|l|l|l|}
\hline Instituições Arquivísticas Estaduais & \multicolumn{1}{|c|}{ Dispositivos 2018 } & \multicolumn{1}{|c|}{ Dispositivos 2020} \\
\hline Arquivo Público do Distrito Federal & $\begin{array}{l}\text { facebook, youtube, flickr, } \\
\text { twitter }\end{array}$ & $\begin{array}{l}\text { facebook, youtube, flickr, } \\
\text { twitter, instagram }\end{array}$ \\
\hline $\begin{array}{l}\text { Arquivo Público Estadual Jordão } \\
\text { Emerenciano (Pernambuco) }\end{array}$ & facebook e instagram & website fora do ar \\
\hline Arquivo Público do Estado de São Paulo & $\begin{array}{l}\text { facebook, twitter, youtube } \\
\text { e instagram }\end{array}$ & $\begin{array}{l}\text { facebook, twitter, youtube } \\
\text { e instagram }\end{array}$ \\
\hline $\begin{array}{l}\text { Arquivo Público do Estado do Rio } \\
\text { Grande do Sul }\end{array}$ & blog, twitter & $\begin{array}{l}\text { twitter, instagram, } \\
\text { facebook }\end{array}$ \\
\hline $\begin{array}{l}\text { Arquivo Público do Estado do Espírito } \\
\text { Santo }\end{array}$ & facebook e instagram & facebook e instagram \\
\hline
\end{tabular}

Fonte: Dados da pesquisa, 2020.

Constatou-se que ainda são poucas as instituições arquivísticas públicas estaduais que disponibilizam um ambiente de interação com os usuários. Segundo Archer e Ciaconni (2010), os dispositivos da web social proporcionam a potencialização nas formas de publicação, compartilhamento e organização de informações, além de possibilitar o aumento da interação e colaboração entre os usuários. Dessa maneira, as instituições arquivísticas, ao não oferecerem esses recursos da web social aos usuários, estão deixando de possibilitar a participação mais ativa deles nas instituições arquivísticas, quando poderiam sugerir melhorias, opinar sobre os produtos e serviços e contribuir para divulgação do papel relevante desses ambientes para a sociedade.

Por outro lado, quando as instituições arquivísticas disponibilizam um espaço de fala e interação, como da web social, como nos casos apresentados no Quadro 3, poderá fortalecer os vínculos com os usuários e despertar neles a responsabilidade de preservar e contribuir com a instituição arquivística, enquanto ambiente de informação, memória, cultura e identidade do seu povo.

Alinhado com o Quadro 3, no Gráfico 1 são apresentados os dispositivos da web social identificados nos websites das instituições arquivísticas públicas estaduais:

Gráfico 1 - Dispositivos de comunicação da web social identificados nos websites das instituições arquivísticas públicas estaduais em 2018 e 2020 


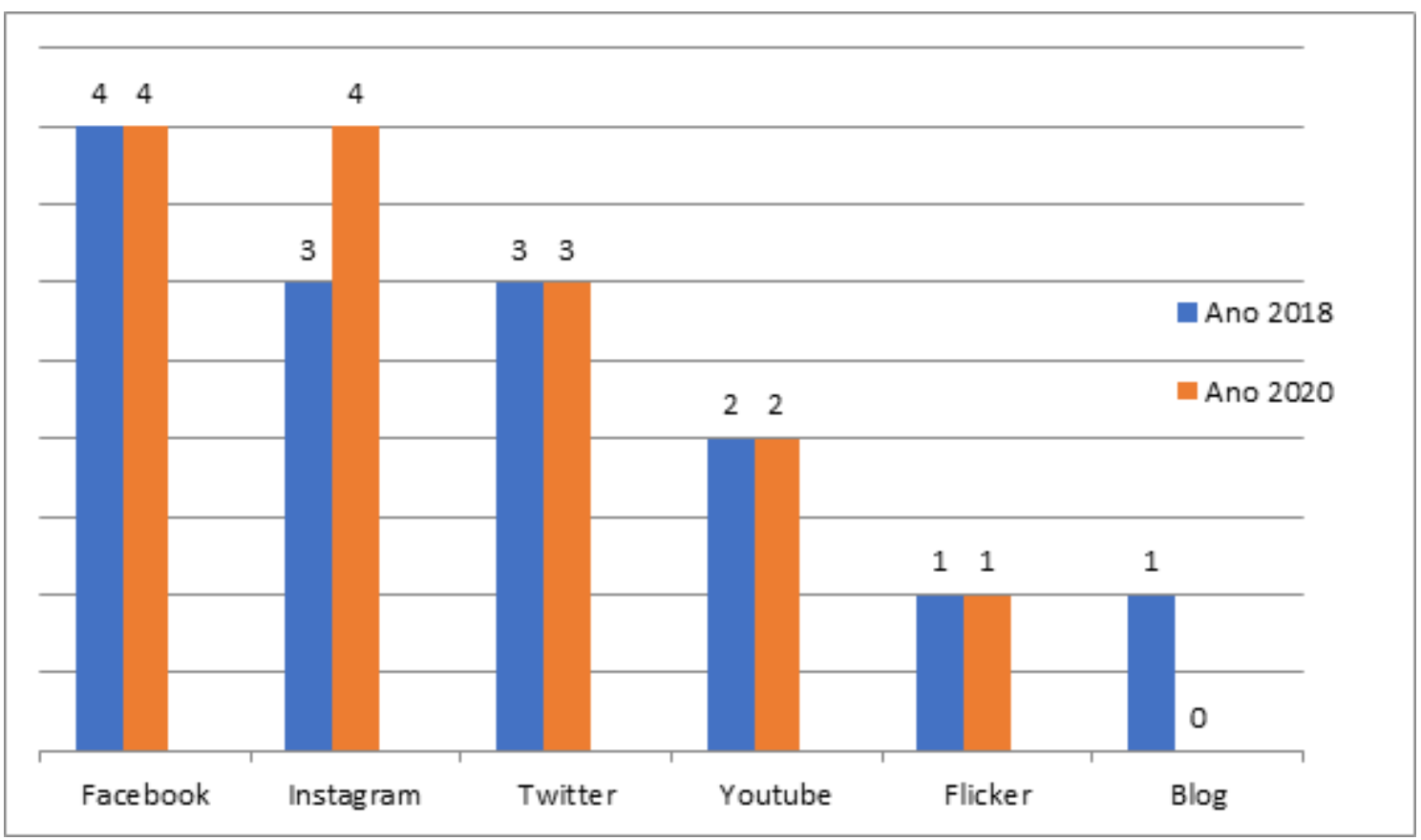

Fonte: Dados da pesquisa, 2020.

Como é possível verificar no Gráfico 1, na realização da primeira pesquisa em 2018, o facebook obteve a quantidade mais expressiva nos websites das instituições arquivísticas públicas estaduais (4). Outros dispositivos também foram utilizados por essas instituições, a exemplo do twitter (3) e do instagram (3). Em 2020, houve uma alteração de dispositivos, sendo explicitada no caso do instagram (4) e do blog (0). Pode-se inferir que, ao adotar esses dispositivos, por suas características, as instituições sinalizam interesse em dialogar e se aproximar dos usuários. (ARCHER; CIACONNI, 2010).

O facebook é o dispositivo da web social que se manteve em quantidade de disponibilização nos websites. Entretanto, conforme o Quadro 4, existem outras instituições arquivísticas que, apesar de utilizarem esse recurso de comunicação da web social, não indicam em seus websites. Assim, em 2018, constatou-se que cinco (5) instituições arquivísticas públicas estaduais brasileiras possuem páginas no facebook sem indicar em seus websites e, em 2020, o número dessas instituições arquivísticas aumentou para seis (6).

\section{Quadro 4 - Instituições arquivísticas públicas estaduais brasileiras que possuem o dispositivo facebook sem informar em seus websites}


Héngret Santos Ferreira, Raquel do Rosário Santos, Louise Anunciação Fonseca de Oliveira do Amaral

O uso dos dispositivos de comunicação da web social pelas instituições arquivísticas públicas estaduais brasileiras

\begin{tabular}{|c|c|}
\hline \multicolumn{2}{|c|}{ Instituições arquivísticas públicas estaduais brasileiras } \\
\hline 2018 & 2020 \\
\hline Arquivo Público Mineiro & Arquivo Público Mineiro \\
\hline Arquivo Público de Alagoas & Arquivo Público de Alagoas \\
\hline $\begin{array}{c}\text { Arquivo Público do Estado do Rio de } \\
\text { Janeiro }\end{array}$ & Arquivo Público do Estado do Rio de \\
\hline Arquivo Público do Estado do Pará & Arquivo Público do Estado do Pará \\
\hline Arquivo Público do Estado do Rio Grande do & Arquivo Público de Santa Catarina \\
\hline Sul & Arquivo Público do Estado do Amazonas \\
\hline
\end{tabular}

Fonte: Dados da pesquisa, 2020.

A partir desse resultado, vale destacar a relevância das instituições vincularem o dispositivo da web social aos seus websites, o que poderá favorecer a divulgação das mesmas e apresentar confiabilidade ao usuário, logo que o website pode ser considerado o ambiente virtual oficial da instituição arquivística. Por outro lado, também pode se exemplificar os casos dos Arquivos Público do Estado do Pará e Público Estadual Jordão Emerenciano (Pernambuco) que, mesmo não disponibilizando um website ativo, ainda assim possuem uma página no facebook. Pode-se inferir que, pela impossibilidade de oferecer um ambiente mais formal, como um website, pois muitas vezes demanda custos, as instituições arquivísticas optaram por adotar o facebook para interagir com o usuário no ambiente virtual.

A partir do panorama apresentado anteriormente, destacando o facebook no âmbito das instituições arquivísticas, foi realizada uma investigação do uso desse dispositivo e, com relevo, quais as informações que são disponibilizadas nesse ambiente.

Em 2018, foi constatado que 9 instituições arquivísticas estaduais brasileiras optaram pelo facebook como dispositivo para interação com 0 usuário. Apesar do facebook permitir que seus usuários escolham entre criar páginas e perfis, o próprio facebook indica que as instituições e empresas criem 
Héngret Santos Ferreira, Raquel do Rosário Santos, Louise Anunciação Fonseca de Oliveira do Amaral

O uso dos dispositivos de comunicação da web social pelas instituições arquivísticas públicas estaduais brasileiras

seus espaços em formato de página, para melhor se adequar a realidade dessas instituições. Assim, as instituições arquivísticas estão dentro dos parâmetros recomendados pelo facebook, o que pode auxiliá-los na disponibilização de informações e desenvolvimento de atividades voltadas aos usuários.

Quanto à atualização das páginas das instituições arquivísticas estaduais brasileiras, com que se refere à frequência destas disponibilizarem informações para seus usuários, apenas uma (1) instituição arquivística atualiza sua fanpage todos os dias e duas (2) atualizam de 1 a 2 dias.

Em 2020, das 11 instituições que incorporaram o facebook, pode-se notar que amplia-se a relevância quanto à atualização dos conteúdos, pois 4 fanpages passam a ter uma frequência maior de atualizações (uma todo dia e 3 delas de 1 a 3 dias). O Quadro 5 apresenta a periodicidade das atualizações realizadas no facebook, no qual pode se destacar também que as demais instituições adotam períodos variados para atualizações, podendo repercutir na visibilidade que o usuário terá dessas páginas. Assim, as fanpages que possuem uma periodicidade regular poderão estimular um acompanhamento e participação maior por parte usuário.

\section{Quadro 5 - Periodicidade de atualização do facebook das instituições arquivísticas estaduais brasileiras}

\begin{tabular}{|l|l|l|}
\hline \multicolumn{1}{|c|}{$\begin{array}{c}\text { Instituições arquivísticas públicas estaduais } \\
\text { brasileiras }\end{array}$} & \multicolumn{1}{|c|}{$\begin{array}{c}\text { Período de } \\
\text { atualização 2018 }\end{array}$} & $\begin{array}{c}\text { Período de } \\
\text { atualização 2020 }\end{array}$ \\
\hline Arquivo Público do Estado de São Paulo & Todos os dias & Todos os dias \\
\hline Arquivo Público do Distrito Federal & De 1 a 2 dias & De 3 a 13 dias \\
\hline $\begin{array}{l}\text { Arquivo Público Estadual Jordão Emerenciano } \\
\text { (Pernambuco) }\end{array}$ & De 1 a 2 dias & De 2 a 18 dias \\
\hline Arquivo Público do Estado do Espírito Santo & De 1 a 3 dias & De 1 a 3 dias \\
\hline Arquivo Público do Estado do Rio Grande do Sul & De 5 a 7 dias & De 2 a 7 dias \\
\hline Arquivo Público de Alagoas & De 1 a 7 dias & De 1 a 3 dias \\
\hline Arquivo Público do Estado do Pará & De 3 a 10 dias & $\begin{array}{l}8 \text { meses que as } \\
\text { publicações não } \\
\text { são atualizadas }\end{array}$ \\
\hline
\end{tabular}


Héngret Santos Ferreira, Raquel do Rosário Santos, Louise Anunciação Fonseca de Oliveira do Amaral

O uso dos dispositivos de comunicação da web social pelas instituições arquivísticas públicas estaduais brasileiras

\begin{tabular}{|l|l|l|}
\hline \multicolumn{1}{|c|}{$\begin{array}{c}\text { Instituições arquivísticas públicas estaduais } \\
\text { brasileiras }\end{array}$} & \multicolumn{1}{|c|}{$\begin{array}{c}\text { Período de } \\
\text { atualização 2018 }\end{array}$} & \multicolumn{1}{c|}{$\begin{array}{c}\text { Período de } \\
\text { atualização 2020 }\end{array}$} \\
\hline \multicolumn{2}{|c|}{ (continuação do Quadro 5) } \\
\hline Arquivo Público do Estado do Rio de Janeiro & De 2 a 10 dias & $\begin{array}{l}\text { Um mês que as } \\
\text { publicações não } \\
\text { são atualizadas }\end{array}$ \\
\hline Arquivo Público Mineiro & De 1 a 10 dias & De 1 a 3 dias \\
\hline Arquivo Público de Santa Catarina & & De 1 a 5 dias \\
\hline Arquivo Público do Amazonas & $\begin{array}{l}2 \text { meses que as } \\
\text { publicações não } \\
\text { são atualizadas }\end{array}$ \\
\hline
\end{tabular}

Fonte: Dados da pesquisa, 2020.

Além da periodicidade, também buscou-se verificar se estas instituições disponibilizavam informações que garantissem conforto aos usuários quanto ao deslocamento ao ambiente físico das instituições arquivísticas, tais como: horário de funcionamento, informações para contato, endereço, dentre outras.

Ao analisar o ano de 2018, as 9 instituições arquivísticas estudadas que utilizavam o facebook, disponibilizavam informações sobre a localização e outros meios de contato que os usuários poderiam utilizar, por exemplo: telefone e email. Como também a maior parte delas (7) informavam aos usuários sobre o horário de funcionamento. Em contrapartida, em 2020, as 11 instituições disponibilizavam tanto as informações de localização, quanto horário de funcionamento e contatos. Constata-se um avanço na incorporação de informações utilitárias sobre o ambiente físico das instituições arquivísticas.

Esse tipo de informação auxilia os usuários a planejarem sua visita, como também o uso dos produtos e serviços no ambiente físico da instituição arquivística, oferecendo um nível de conforto aos usuários, pois Mariz (2012, p. 104) diz que "Uma divulgação sobre uma instituição arquivística que não ensina como se chega a ela é incompleta e não se efetiva."

No ano de 2018, quanto às informações sobre a equipe de colaboradores das instituições arquivísticas estaduais brasileiras, apenas duas delas - Arquivo Público do Estado do Espírito Santo e Arquivo Público de Alagoas - possuem alguma informação sobre membros da equipe. Em 2020, percebeu- 
se que apenas o Arquivo Público do Estado do Espírito Santo apresentava essa informação. Apesar dessa informação ser importante, para que o usuário possa conhecer quem compõe a equipe da instituição, quais as funções que essas pessoas desempenham nesse espaço e com quem pode contactar para auxiliálos, percebeu-se a necessidade das instituições arquivísticas estaduais atentarem-se para a disponibilização dessas informações.

Em 2018, quanto à disponibilização de outros dispositivos, a partir da página do facebook das instituições arquivísticas estaduais, quase a metade das instituições analisadas (4) vinculam outros dispositivos da web social à sua fanpage. Por sua vez, em 2020, também constatou-se uma diminuição (2) dos casos de instituições que atrelavam a fanpage à outros dispositivos. Infere-se que existe uma contradição nessa atitude, visto que constata-se um incremento na disponibilização simultânea de conteúdos em mais de um dispositivo da web social. Esse tipo de ação auxilia na ampliação da disseminação da informação, em diferentes formatos, além de alcançar usuários que utilizam outros dispositivos.

Por fim, vale ainda destacar que sobre a disponibilização dos endereços eletrônicos dos websites das instituições arquivísticas estaduais, apenas o Arquivo Público do Estado do Pará não tem em sua fanpage o link que possibilita o acesso ao seu site, por essa instituição não possuir este último recurso, tanto em 2018 quanto em 2020. Em 2020, constatou-se que o Arquivo Público do Estado de Santa Catarina também não possui o link que possibilita o acesso ao seu site. Por sua vez, o Arquivo Público Estadual Jordão Emerenciano (Pernambuco), apesar de disponibilizar o endereço eletrônico para o seu site, por meio do facebook, encontra-se fora do ar. Assim, nos demais casos analisados, o usuário pode complementar a sua busca por informações, alternando entre esses dois dispositivos de comunicação na web.

\section{CONSIDERAÇÕES FINAIS}

Os resultados desta pesquisa sinalizam que os gestores das instituições arquivísticas estaduais brasileiras precisam se tornar ativos e conscientes sobre 
Héngret Santos Ferreira, Raquel do Rosário Santos, Louise Anunciação Fonseca de Oliveira do Amaral

O uso dos dispositivos de comunicação da web social pelas instituições arquivísticas públicas estaduais brasileiras

a importância de disponibilizar um espaço formal na web social que garanta a interação e colaboração com o usuário.

Quanto à verificação se as instituições arquivísticas estaduais possuíam dispositivos de comunicação da web social e quais eram esses dispositivos, ficou evidenciado que, apenas 5 das 18 instituições listadas em 2018, disponibilizavam informações em seus sites sobre os dispositivos que utilizavam. Em contrapartida a esse cenário, em 2020, constatou-se que apenas 4 das 16 instituições arquivísticas públicas disponibilizavam essas informações em seus websites. Assim, com essa redução, pôde-se perceber que as instituições arquivísticas estaduais ainda não se atentaram para a utilização e/ou divulgação desses dispositivos e/ou ainda não os incorporaram na gestão.

Outro fator interessante, evidenciado em 2018, é que o facebook obteve uma quantidade expressiva de utilização pelas instituições arquivísticas, se mantendo também em 2020. Essa manutenção se dá também com o instagram. Nesse processo de adoção dos múltiplos dispositivos, cada instituição deve se atentar para o perfil dos seus usuários e também os objetivos relacionados ao seu processo gestão arquivística.

Além da inserção nesse espaço virtual, no caso do facebook, as instituições arquivísticas precisam notar a importância de oferecerem as informações básicas de seus espaços físicos como: a localização, os contatos por telefone e e-mail, histórico, a equipe que compõe e atua na instituição, além de manter uma atualização frequente das informações no facebook e demais recursos da web social.

Ao analisar os anos, avanços e desafios foram percebidos no que tange ao uso dos recursos na web. Entre os avanços, destaca-se que as instituições arquivísticas estão mais atentas aos dispositivos da web social mais utilizados pelos seus usuários, a exemplo do facebook, instagram e twitter. Além disso, no contexto do facebook, constata-se um avanço na incorporação de informações utilitárias sobre o ambiente físico das instituições arquivísticas.

Mesmo com os avanços identificados, como desafios, é preciso ampliar a incorporação dos dispositivos da web social, bem como a regularização da 
Héngret Santos Ferreira, Raquel do Rosário Santos, Louise Anunciação Fonseca de Oliveira do Amaral

O uso dos dispositivos de comunicação da web social pelas instituições arquivísticas públicas estaduais brasileiras

periodicidade na atualização dos conteúdos. Por fim, é importante o aumento de identificação dos websites das instituições arquivísticas.

\section{REFERÊNCIAS}

ARCHER, L.; CIANCONI, R. B. Websites dos Arquivos Públicos: funções exercidas e recursos de colaboração e interação com os usuários. Inf. Inf., Londrina, v.15, n.2, p. 60-76, jul./dez. 2010. Disponível em: http://www.uel.br/revistas/uel/index.php/informacao/article/view/5752. Acesso em: 12 março 2018.

ARQUIVO NACIONAL (Brasil). Conselho Nacional de Arquivos. 2018.

Disponível em: http://conarq.arquivonacional.gov.br/o-cadastro.html. Acesso em: 16 abr. 2018.

BELLOTO, H. L. Arquivo: estudos e reflexões. Belo Horizonte: Editora UFMG, 2014. 447p.

CORTÊS, M. R. P. A. Arquivo público e informação: acesso à informação aos arquivos públicos estaduais do Brasil. Dissertação (Mestrado em Ciência da Informação) - Escola de Biblioteconomia, Universidade Federal de Minas Gerais, Belo Horizonte, 1996. Disponível em: http://www.bibliotecadigital.ufmg.br/dspace/handle/1843/BUOS-96UPHB. Acesso em: 12 jun. 2018.

DUARTE, A. B. A. Redes Sociais: uma nova perspectiva para a difusão do patrimônio arquivístico público. 2013. 116f. Trabalho de conclusão (graduação em Arquivologia) - Faculdade de Biblioteconomia e Comunicação, Universidade Federal do Rio Grande do Sul. Porto Alegre, 2013. Acesso em: 12 mar. 2018

GARCIA, T. X.; VIEIRA, A. F. G. Biblioteca 2.0: levantamento do seu uso em bibliotecas. Ciencias de la Información, v. 41, n.2, maio/ago., p. 17-26, 2010. Disponível em: https://biblat.unam.mx/pt/revista/ciencias-de-lainformacion/articulo/biblioteca-2-0-levantamento-do-seu-uso-em-bibliotecas. Acesso em: 12 mar. 2018.

GIL, A. C. Como elaborar projetos de pesquisa. 4. ed. São Paulo: Atlas, 2002.

JARDIM, J. M. A Construção de uma Política Nacional de Arquivos: os Arquivos Estaduais Brasileiros na ordem democrática (1988-2011). In: ENCONTRO NACIONAL DE PESQUISA EM CIÊNCIA DA INFORMAÇÃO, 12. 2011, Brasília, DF. Anais[...]. Brasília, DF: UNB, 2011. 
JORENTE, M. J. V.; BATISTA, L. S. Conversações entre a rede social twitter e os arquivos permanentes: um estudo de curadoria digital. Inf. Inf., Londrina, v. 22, n. 1, p. 5-33, jan./abr., 2017. Disponível em: http:www.uel.br/revistas/informacao/. Acesso em: 12 mar. 2018

MARIZ, A. C. A. A informação na internet: arquivos públicos brasileiros. Rio de Janeiro: Editora FGV, 2012. 168 p.

MAZZOTTI, A. J. A. Usos e Abusos dos Estudos de Caso. Cadernos de Pesquisa, São Paulo, v. 36, n. 129, p. 637-651, set./dez. 2006. Disponível em: https://www.scielo.br/pdf/cp/v36n129/a0736129.pdf. Acesso em: 23 jun. 2018.

NASCIMENTO, T. G.; QUINTÃO, P. L. Ferramentas da web 2.0 para a gestão do conhecimento em um ambiente organizacional. Revista Eletrônica da Faculdade Metodista Granbery, Juiz de Fora, n. 10, p. 1-26, jan./jun. 2011. Disponível em: http://re.granbery.edu.br/artigos/NDM1.pdf. Acesso em: 11 ago. 2019.

OLIVEIRA, L. A. F. O uso das ferramentas web 2.0 na gestão de instituições arquivísticas nacionais de tradição ibérica: uma reflexão sobre a cultura participativa. 2012. 260 p. Dissertação (Mestrado em Ciência da Informação) - Programa de Pós-Graduação em Ciência da Informação, Instituto de Ciência da Informação, Universidade Federal da Bahia, Salvador, 2012.

PALETTA, F. C.; MUCHERONI, M. L. O desenvolvimento da WEB 3.0: Linked Data e DBPEDIA. Prisma.Com, Porto, v. 25, 2014, p. 73-90. Disponível em: http://www3.eca.usp.br/sites/default/files/form/biblioteca/acervo/producaoacademica/002678477.pdf. Acesso em: 18 maio 2020.

SCHELLENBERG, T.R. Arquivos Modernos: princípios e técnicas. 6 ed. Rio de Janeiro: Editora FGV, 2006. 388p.

SILVA, J. G. Socialização da informação arquivística: a viabilidade do enfoque participativo na transferência de informação. 1996. 99p. Dissertação (Mestrado) - Universidade Federal do Rio de Janeiro, Rio de Janeiro, 1996.

SILVA, J. G.; MARINHO JÚNIOR, I. Arquivos e Informação: uma parceira promissora. Arquivo \& Administração. Rio de Janeiro, v.1, jan/jun, 1998.

SOUZA, K. I. M.; CÂNDIDO, F. O. Um novo olhar pelas páginas dos arquivos públicos estaduais brasileiros. Informação Arquivística, Rio de Janeiro, v. 3 , n. 2, p. 102-114, jul./dez., 2014.

\section{THE USE OF SOCIAL WEB COMMUNICATION DEVICES BY THE BRAZILIAN STATE ARCHIVAL INSTITUTIONS}




\begin{abstract}
Objective: Analyze if and as state archival institutions has been using the devices of communication of the social web to favor the access to the information to the user. The following topics are adopted and discussed: state archival institutions; social web and social web communication devices. Methodology: This is a descriptive, qualitative and quantitative study, carried out using the multiple case method, whose object is to study Brazilian state archival institutions, more specifically their social web communication devices. The electronic address of these archives was obtained through the list of state archival institutions available on the National Council of Archives (CONARQ) website, being the second stage a direct observation on the websites and, finally, an observation in the fanpage of archival institutions. Results: As a result, it was identified which state archival institutions make available the social web communication devices, what these devices are and how the use of social web devices by state archival institutions has been occurring. Conclusions: That managers need to become active and aware about the importance of providing a formal social web space that guarantees user interaction and collaboration.
\end{abstract}

Keywords: State Archives. Social web - archive. Social Web Communication Devices Archive.

\title{
EL USO DE LOS DISPOSITIVOS DE COMUNICACIÓN DE LA WEB SOCIAL POR LAS INSTITUCIONES ARQUIVISTICAS PÚBLICAS ESTADUALES BRASILEÑAS
}

\begin{abstract}
RESUMEN
Objetivo: Analizar si y cómo las instituciones públicas públicas estatales vienen utilizando los dispositivos de comunicación de la web social para favorecer el acceso a la información al usuario. Siendo adoptadas y discutidas las siguientes temáticas: instituciones archivísticas públicas estatales; dispositivos de comunicación web social y web social. Metodología: Se trata de un estudio de carácter descriptivo, con naturaleza cualitativa y cuantitativa, realizado por medio del método de múltiples casos, teniendo como objeto de estudio las instituciones archivísticas públicas estatales brasileñas, más específicamente sus dispositivos de comunicación de la web social. La dirección electrónica de estos archivos fue obtenida por medio de la lista de instituciones archivísticas estatales disponibilizada en el sitio web del Consejo Nacional de Archivos - CONARQ, siendo la segunda etapa una observación directa en los websites, y por último, una observación en la fanpage de las instituciones archivísticas. Resultados: Se identificó cuáles las instituciones archivísticas públicas estatales disponibilizan los dispositivos de comunicación de la web social, cuáles son esos dispositivos y cómo viene ocurriendo el uso de los dispositivos de la web social por las instituciones archivísticas estatales. Conclusiones: Los gestores necesitan hacerse activos y conscientes sobre la importancia de poner a disposición un espacio formal en la web social que garantice la interacción y colaboración del usuario.
\end{abstract}


Héngret Santos Ferreira, Raquel do Rosário Santos, Louise Anunciação Fonseca de Oliveira do Amaral

O uso dos dispositivos de comunicação da web social pelas instituições arquivísticas públicas estaduais brasileiras

Descriptores: Archivos Públicos Estaduales. Web social - archivo. Dispositivos de comunicación de la Web social - archivo.

Recebido em: 18.02 .2020

Aceito em: 07.05.2020 